\title{
As hérnias
}

\section{medem-se aos palmos?}

\section{How large are hernias?}

Apresenta-se o caso de uma doente do sexo feminino com 74 anos, autónoma, com antecedentes patológicos de obesidade, diabetes mellitus tipo 2, hipertensão arterial e doença osteoarticular degenerativa, que recorreu à urgência por infeção respiratória inferior. Negava sintomas gastrointestinais ou antecedentes cirúrgicos. Ao exame objetivo, destacava-se a presença de uma hérnia umbilical volumosa não dolorosa à palpação, mas que condicionava a sua mobilidade, sendo impossível a redução do conteúdo herniário. Após insistência na anamnese, a doente referiu o seu aparecimento na infância, na altura com recusa em efetuar a sua correção cirúrgica, tendo sido perdido o seu seguimento posteriormente. A radiografia e a tomografia computorizada abdominais mostraram um colo herniário de seis centímetros de diâmetro e herniação de praticamente todo o intestino delgado e parte do cólon, sem evidência de encarceramento (Figuras 1 e 2).

Apesar de décadas de evolução condicionarem um progressivo e forte impacto nas atividades da vida diária, a doente não procurou os cuidados de saúde por esse motivo, mantendo a sua decisão e sendo encaminhada para a consulta externa.

As complicações herniárias abdominais incluem a obstrução intestinal e a temida emergência cirúrgica da hérnia encarcerada, não se desprezando a morbilidade inerente, bem evidente neste caso. ${ }^{1-2}$

\section{Bibliografia}

1. Parvanescu H. Large Right Inguinal Hernia. N Engl J Med. 2013; 368:171.

2. Tahir M, Ahmed FU, Seenu V. Giant inguinoscrotal hernia: Case report and management principles. Int J Surg. 2008; 6:495-7.

\section{Diagnóstico}

\section{Hernia abdominal volumosa}

\section{Cátia Pereira, Tânia Afonso}

Serviço de Medicina Interna, Unidade Local de Saúde do Nordeste, Bragança, Portugal.

Correspondencia: cmlpmed@gmail.com

Cómo citar este artículo: Pereira C, Afonso $T$

As hérnias medem-se aos palmos?. Galicia Clin 2016; 77 (2): 82

Recibido: 13/12/2015; Aceptado:10/01/2016
Figura 1. Hérnia abdominal em radiografia abdominal.

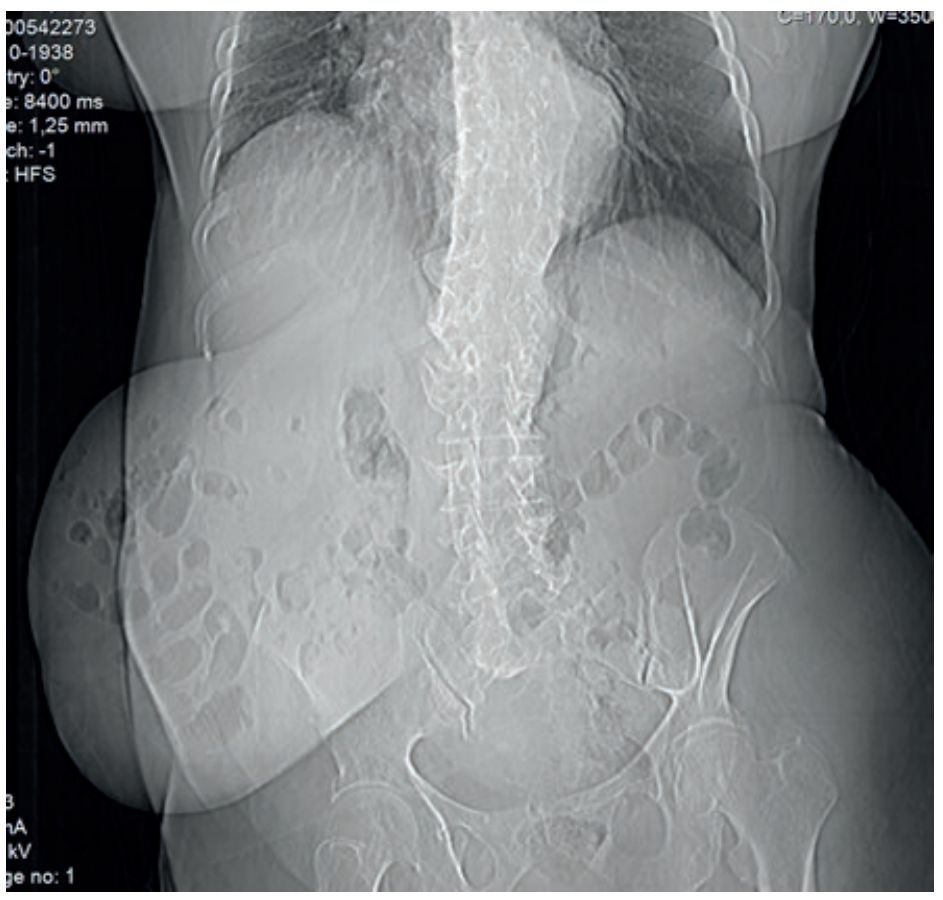

Figura 2. Hérnia abdominal não encarcerada com colo herniário de $60 \mathrm{~mm}$.

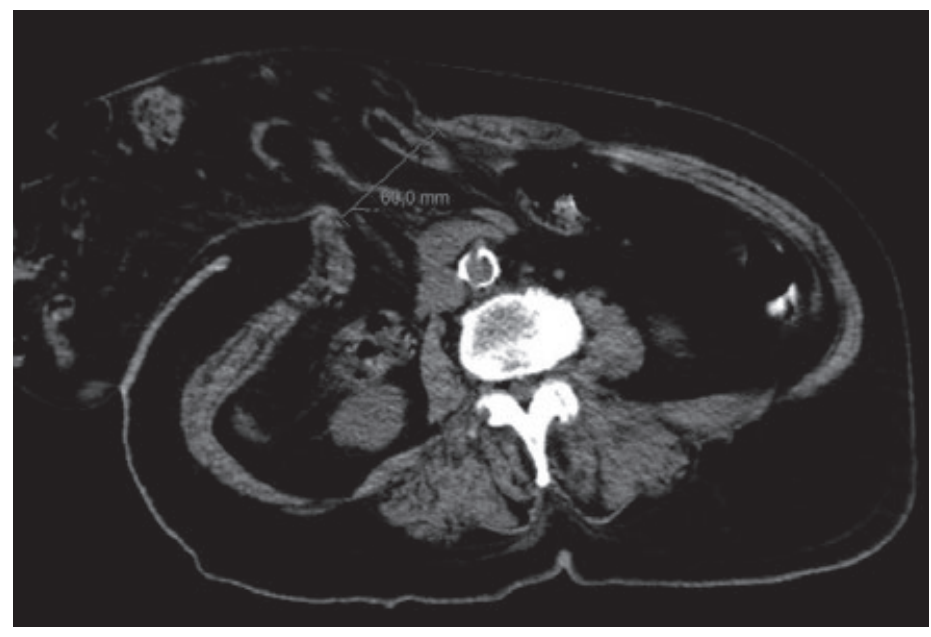

